\title{
Virtual Reality in TEFL Context, Instructors' Perspectives in a Saudi University
}

\author{
Mohammad Ali Al-Gamdi ${ }^{1}$ \\ ${ }^{1}$ Department of English Language, Faculty of Arts and Science, Al Baha University, Saudi Arabia \\ Correspondence: Mohammad Ali Al-Gamdi, Department of English Language, Faculty of Arts and Science, Al \\ Baha University, Saudi Arabia. E-mail: Masaleh@bu.edu.sa
}

Received: February 13, 2019 Accepted: March 11, 2019 Online Published: May 23, 2019

doi:10.5539/ells.v9n2p25 URL: https://doi.org/10.5539/ells.v9n2p25

\begin{abstract}
The purpose of this study is to explore instructors' perspectives in a Saudi university about using virtual reality in TEFL context. The sample of the study consisted of 6 instructors randomly selected from different faculties affiliated to Al-Baha University. The instrument of the study is based on semi-structured interviews administered to the targeted participants. The researcher used SWOT analysis to process the elicited data. The Findings of the study indicate that strength points of using virtual reality to teach English are VR is exciting, authentic, and more interactive learning style for English language learners as compared to conventional learning style, weakness points are financial setbacks of implementing VR and the inexperienced instructors who need training to implement VR to teach English. The results indicate that there is only one main threat of using VR to teach the English language in the Saudi context, namely that VR could be a distraction for some students. This study generates new insights into processes of adopting VR to teach English language in the Saudi context and the potential strength, weakness, opportunity, and threats to such adoption in the target university. The study concluded with recommendations to the concerned institutions for the betterment of using VR in EFL contexts. The researcher suggests further studies to be conducted in similar contexts for using VR in EFL institutions.
\end{abstract}

Keywords: virtual reality, CALL, TEFL, Saudi context, higher education

\section{Introduction}

The development of technology has contributed to enhancing teaching and learning with the help of providing new approaches for acquiring knowledge and developing skills. The use of different types of technology is typical of modern learning environments because young people are interested in digitally mediated modes of learning that provide them with more opportunities to improve their capacities (Godwin-Jones, 2016). This phenomenon is associated with teaching languages, including the English language. The incorporation of technology in classrooms has led to developing new methodologies of working with devices to teach languages, but there is no single opinion regarding the effectiveness of applying technology to learning (Kessler, 2018). In the recent literature on the adoption of technologies in learning environments, much attention is paid to discussing the application of virtual reality as an innovative approach to teaching languages. The purpose of this study is to highlight virtual reality in TEFL context, with reference to instructors' perspectives in a Saudi university; it also aims to discuss the use of technology in teaching and learning languages with the focus on possible advantages and disadvantages and analyze the application of virtual reality to teaching the English language with reference to potential benefits and drawbacks.

\section{Literature Review}

\subsection{Using Technology to Teach Languages}

The use of technology in teaching languages is associated with applying a range of specific principles and rules to achieve positive outcomes for learners. Currently, when teaching languages instructors choose to apply audiobooks, ePortfolios, mobile applications, presentations, blogs, websites, virtual platforms, video games, and other media to enhance learning of their students and make it more instant and motivating (Golonka, Bowles, Frank, Richardson, \& Freynik, 2014; Kessler, 2018). According to Chun, Kern and Smith (2016), modern teachers need to be concentrated on the context of mediation while applying technologies to correlate the use of computers, mobile devices, projectors, recorders, screens, and software in their environment while teaching 
languages. Thus, technologies are typically used for improving such activities as listening, speaking, writing, composing, and reading.

If audiobooks, video materials, and presentations among other tools are viewed as common applications of technology in a language-learning environment, the utilization of blogs, websites, social media, simulations, video games, online platforms, and other similar resources for enhancing linguistic skills are discussed in the context of computer-assisted language learning (CALL). Thus, CALL allows educators to provide students with more effective and various resources to improve their learning of the English language with the help of modern devices (Golonka et al., 2014; Kessler, 2018). In this context, CALL is needed for using authentic language samples, improving learners' pronunciation, communicating with native speakers, and practicing language actively (Lin \& Lan, 2015). Today, teachers often choose to expand the boundaries of their classrooms with the help of technologies, and they use different virtual platforms for participating in telecollaborative projects or imitating traveling, for example (Chun et al., 2016; Kessler, 2018). These innovative approaches to teaching languages allow for receiving authentic practical experiences.

Teachers use virtual learning platforms like Blackboard, Moodle, and applications such as Skype, Facebook, and wikis to organize a teaching-learning process and promote computer-mediated communication associated with the constant development of language skills. The use of such platforms and resources allows teachers to vary the media for working with students to improve their experience and practice of languages (Golonka et al., 2014; Lin $\&$ Lan, 2015). In this regard, the application of course management systems, Blackboard and Moodle for example, is important for changing a traditional process of studying languages to make it more contemporary and addressing current social tendencies and needs of learners.

In the same breath, by using technologies, students train their skills in reading comprehension, vocabulary development, speaking, listening, and grammar referring to the most innovative approaches and techniques. However, opposite results regarding the application of technology in teaching and learning languages are also presented in studies, and they need to be discussed in detail (Chun et al., 2016; Kessler, 2018). In spite of the fact that all these available technologies and the use of computer-mediated communication in teaching languages can contribute to developing students' literacy and linguistic skills, the process of applying digital resources and devices is often challenging for teachers. The reason is that it is necessary to effectively organize computer-based settings and processes of teaching to guarantee positive results.

\subsection{Pros and Cons of Using Technology to Teach Languages}

Although the use of technology in teaching languages is used as an important step toward motivating students, developing a learner-centered education, and addressing the trends of a modern world, there are different views regarding this practice. Those researchers and instructors who support the use of technologies for teaching languages, including English, mention the following arguments: students' increased attention, improved vocabulary knowledge, and the focus on meaningful learning among others (Freina \& Ott, 2015). Advantages of using technologies in teaching languages include the development of students' creativity and intellectual skills depending on their personal learning style (Kessler, 2018). Other advantages of applying technology for teaching language learners include the possibility to realize distant communication with the help of a possibility to interact both synchronously or asynchronously to achieve better outcomes (Chun et al., 2016), Many researchers seem to agree that technological innovations are effective to influence students' motivation and interest in learning the English language, as well as other languages, with the help of a variety of offered digital tools.

While referring to the other arguments of promoters of CALL, one should note that the strengths of technology application to teaching languages are mainly associated with providing educators with a variety of tools and methodologies to stimulate their students to learn. The process of learning a foreign language is often viewed as challenging, students often cannot concentrate on tasks, have problems with remembering words, lack practice in pronouncing and listening, and cannot easily communicate with each other (Chun et al., 2016; Golonka et al., 2014). According to Kessler (2018), the use of technologies as additional to paper books and traditional resources can help educators overcome most of these issues while increasing students' interest in learning. Language teachers try to apply computer-based approaches to language learning for the purpose of encouraging students' active involvement in the process with the focus on their motivation that allows for developing their communicative competence.

Technologies allow for focusing on such critical aspects as social interactivity, availability, portability, and context sensitivity in learning languages. Consequently, using their mobile devices, students can be involved in learning English any time they want without being dependent on their location (Bonner \& Reinders, 2018). Technology-enhanced language learning is viewed by researchers and practitioners as an essential step toward 
modernizing the approach to teaching students (Chun et al., 2016; Golonka et al., 2014). In this context, the focus is on stimulating learners' active communication and studying vocabulary and grammar within a positive and learner-centered computer-mediated environment.

However, there are also opponents of the extensive use of technology in teaching languages who support traditional approaches and techniques. One of the reasons of opposing the active use of devices and digital resources in the language acquisition process is a possible negative effect of using technologies on learners' literacy and independent thinking (Bonner \& Reinders, 2018; Golonka et al., 2014). Causes of decreasing literacy and critical thinking skills in language learners can include unlimited access to information available online that does not contribute to students' thinking and problem-solving. According to the results of the study conducted by Golonka et al. (2014), there is limited evidence to support the effectiveness of using technologies in teaching languages, and only some of the offered techniques can really contribute to improving students' results. These techniques and approaches include the use of computer-based pronunciation training and the use of chats (Golonka et al., 2014). Thus, it is rather problematic to assert that all technologies can have a similar positive effect on teaching and learning languages.

Opponents of the idea of using technologies in educational environments state that a high number of devices, gadgets, and other digital resources involved in a teaching-learning process can be distracting for students who can be concentrated on the form of used media rather than on content. This idea is in disagreement with the results of other studies where a positive impact of technologies on learners' concentration is indicated in their educational achievement (Chen, 2016; Golonka et al., 2014; Kessler, 2018). In addition, the problem is that many educators lack developed skills to effectively integrate technologies into their class activities while decreasing their efficacy (Bonner \& Reinders, 2018). One more point discussed in the literature is that teachers require additional training to work with innovative technologies, but there are limited resources to provide them with this opportunity (Merchant, Goetz, Cifuentes, Keeney-Kennicutt, \& Davis, 2014). Consequently, the use of new technologies in a teaching process can lead to affected interactions, the distraction from tasks, and students' inability to learn a language appropriately if teachers have no required training and practice in using digital resources.

\subsection{What is Virtual Reality}

Virtual reality is also known in education as augmented reality that is characterized by creating a contextual place where different characters can interact within a certain virtual space. Speaking about virtual reality, researchers mean the use of "any simulated, artificial, or synthetic environment that creates a convincing presentation of a desired space" (Kessler, 2018, p. 213). The main idea behind virtual reality is the creation of a simulation for learners to contribute to developing practical skills in a particular context (Fowler, 2015). Thus, the principle of virtual reality is actively used in different disciplines, including languages, mathematics, physics, and medicine among others, for the purpose of providing learners with experiences that they can get only while practicing.

Traditional simulations and educational software used for learning languages and other activities can be currently replaced with the use of virtual reality embedded in applications to create unique virtual worlds. In spite of a comparably high price of devices and resources that are used for creating virtual realities, their costs constantly decrease along with the further improvement of technologies (Garrido-Iñigo \& Rodríguez-Moreno, 2015). Thus, educators started to use virtual reality for teaching different subjects with the help of creating and applying specific scenarios and storyboards that allow for designing a unique virtual space for learning (Fowler, 2015; Morrison, 2017). Virtual reality is perceived as a unique three-dimensional environment for young people to promote their interaction and vocabulary acquisition while speaking about learning languages and other disciplines.

The examples of virtual and augmented reality include various digital games that are similar in their principles and work to Pokémon Go or other realities created with the help of PlayStation VR and HTC Vive. Moreover, Pokémon Go was even adapted to learning English by some educators because of its popularity and interactivity (Bonner \& Reinders, 2018). Therefore, "many of the ways in which language teachers have enlisted the playing of the game [Pokémon Go] in the service of learning could apply to other commercial mobile games" because "this enables possible integration of learning into a fun activity in which learners are engaged by their own choice" (Godwin-Jones, 2016, p. 10). Augmented reality can provide learners with even more unique experiences than common virtual or mediated reality because of a close connection between real reality, real-time, and changed virtual reality in the world of games similar to Pokémon Go.

In the same breath, focusing on the benefits of creating multi-user virtual environments for education, researchers state that virtual reality is important for providing students with opportunities to study in a highly contextualized setting. Accordingly, students become motivated and involved in collaborative learning in a 
common and shared virtual space without being limited by any distance (Li, Tsai, Chen, Cheng, \& Heh, 2015). The use of computers, laptops, tablets, applications, and smartphones is enough to teach and learn any subject with the help of such technology as virtual reality and achieve high results under control of instructors and other peers who can be located in any place of the world.

\subsection{Virtual Reality in TEFL Context}

The use of virtual reality is not viewed as a conventional approach to teaching the English language; therefore, controversies are observed in research and debates on this issue. The example of virtual reality that can be used for teaching languages is the "location-based murder mystery game that was designed to teach Spanish and provide learners with a reason to engage" (Kessler, 2018, p. 213). Such realities are presented in the form of games, applications, and platforms, and they provide teachers of languages with opportunities to create a unique learning context for their students who develop skills while operating in spaces and worlds that reflect actual ones.

The reference to virtual reality is often discussed as important to help learners concentrate on culturally specific or authentic tasks and receive a unique cultural experience while being involved in the target language immersive context. These online or digital environments are characterized by a high level of visual appeal for English learners to provoke their interest in language-oriented activities, and they provide young persons with a variety of interactive tools to use English and cooperate with the help of their avatars in these virtual worlds (Rahimi, Golshan, \& Mohebi, 2014). The creation of virtual reality for teaching English is associated with building a unique multi-user simulated environment that can have three-dimensional effects where several participants or players can easily interact, developing their language skills (Solak \& Cakir, 2015). In this case, distances cannot negatively affect their communication in a specific user-generated space. Moreover, communication in virtual spaces cannot be limited only to using texts, and audio messages can also be used on different platforms. Otherwise, communication between players can be realized with the help of applications that are similar to Skype in their work.

Nevertheless, not all researchers support the idea that virtual reality can contribute to learners' progress more than other approaches to using technology in teaching English. According to the results of the study by Merchant et al. (2014), games can be viewed as more effective for promoting students' learning than different types of simulations and virtual spaces. Moreover, the researchers stated that the performance of students is higher when they are involved in playing games individually rather than in a group (Merchant et al., 2014). These findings oppose other researchers' ideas that collaborative learning promoted with the help of technologies, including virtual reality, can significantly contribute to learning languages.

In addition, while speaking about virtual reality in classrooms, researchers have opposite ideas regarding its role in contributing to students' concentration or distracting them. According to Gadelha, "by blocking out visual and auditory distractions in the classroom, VR [virtual reality] has the potential to help students deeply connect with the material" (as cited in Bonner \& Reinders, 2018, p. 36). This feature is important to assist learners to pay more attention to what they study when developing their skills in the English language. Additional contexts created with the help of virtual reality technologies allow students to focus on understanding linguistically specific details, apply their knowledge depending on simulated situations, and experience a high level of immersion.

According to the results of different studies on applying virtual reality to teaching the English language, there is no strict evidence that this approach is more suitable or effective for developing learners' language skills than classroom learning or the use of other technologies. Researchers note that the most evident results in improving language knowledge and the development of skills while using virtual reality are associated with enhancing certain separate areas: listening, speaking, or writing, for example (Freina \& Ott, 2015; Godwin-Jones, 2016; Morrison, 2017). Thus, students often report that their vocabulary, speaking skills, or reading comprehension have improved with the help of particular activities available through the space of simulations or virtual reality games.

Additionally, much attention is also paid to the emotional aspect of learning English with the help of specific features of virtual reality. According to the results of certain studies, young people prefer this innovative approach to developing their language skills because of positive associations with activities, the absence of boring tasks, and the overall dynamic setting connected with an interesting content (Chen, 2016). The reference to virtual reality can be discussed as an effective choice for the teachers of English when they want to contribute to their students' motivation and interest.

Students often choose the most innovative technologies for learning because they use many devices and various software and applications in their daily life. Therefore, the majority of students have a positive attitude regarding 
the use of different technologies as part of a studying process. It is easy and appropriate for a new generation of students to use tablets, smartphones, and laptops in classes actively, as well as to play games with augmented reality (Lin \& Lan, 2015). Virtual reality should not be viewed as something unfamiliar for young people because they regularly interact with each other using similar technologies (Kessler, 2018). The application of this resource for teaching English is a perfect choice to increase students' attention and provoke their interest and concentration.

In spite of the fact that researchers cannot agree on the overall effectiveness of virtual reality for teaching the English language, they accentuate some areas where the application of the most innovative digital tools for developing students' communication and linguistic capacities can be reasonable. Only virtual or augmented reality can simulate the details of a physical world for students while providing them with a specific cultural and language context to stimulate their communication in English (Li et al., 2015; Morrison, 2017). Immersive and contextual games provide learners with specific experience and training that usually cannot be achieved with the help of traditional instruction in a classroom.

\section{Methodology}

\subsection{Research Design and Context of the Study}

The purpose of this study is to explore instructors' perspectives in a Saudi university about using virtual reality in TEFL context. The sample of the study consisted of 6 instructors randomly selected from different faculties affiliated to Al Baha University. The instrument of the study is based on semi-structured interviews administered to the targeted participants. The researcher used SWOT analysis to process the elicited data. The researcher uses qualitative methodology as it is used according to according to Flick (2018) and Gray (2013) to gain a deep, intense overview of the context of the study. Guthrie (2010) reported that semi-structured interviews allow the interviewer to set a list of issues and interview questions to be covered. The researcher used random sampling to recruit participants for this study. Thus, the researcher used the IT support at the target university in sending emails to all EFL instructors with attached consent letter and Info departments. SWOT analysis (strength; weakness; opportunity and threats, Fine, 2009) was used to construct the semi-structured interviews as well as to analyze the collected data. The interview questions were set in light of the analysis components mentioned above. The context of the study is Al Baha University which is a novice university located in Al Baha Province in the south-west of Saudi Arabia; relatively considered as remote area.

\subsection{Limitation of the Study}

The limitation of the study lies in the fact that it focuses on only one novice Saudi university. The inclusion of other similar Saudi universities would have allowed for more cross-comparison, and better supported a generalization of the research results. However, due to time constraints, limited resources, and the fact that these novice universities are spread in remote areas within Saudi Arabia, this study opens a window for future studies.

\section{Findings of the Study}

Participants were asked to respond to questions focusing on strength; weakness; opportunity and threats of using virtual reality in TEFL context in a Saudi university, findings of the six interviews are categorized based on the responses on these four main questions:

\subsection{What Could Be the Strength Points of Virtual Reality Classes to Teach English?}

The cited strengths of using VR to teach English complemented the reviewed literature in that VR is proposed to provide more fun (Godwin-Jones, 2016), exciting (Chun et al., 2016; Rahimi et al., 2014), authentic (Chun et al., 2016; Kessler, 2018; Rahimi et al., 2014), and more interactive learning style for English language learners as compared to conventional learning (Lin \& Lan, 2015; Solak \& Cakir, 2015).

The following responses by participants demonstrate these four strength points:

- Quotes demonstrating VR as an interactive learning style:

'The strengths points of VR that it provides better chances of more interaction.'

'VR provides better chances of more interaction'

- Quotes indicating VR as an exciting and entertaining learning style:

'VRC is an excitement factor to any English language learning or teaching class, i.e. it can be the best translation of "English through fun" motto.'

'Add a kind of entertainment to the process of learning or teaching.' 
- Quotes showing VR as an authentic learning experience:

'VR might expose learners to more authentic materials.'

'VRC can be a breakthrough to authentic English away from the discreet skills of traditional methods of teaching/learning English.'

'Virtual Reality Classes (VRC) stimulate real-life situations for students to lively interact with the discreetly-chosen components of an English lesson.'

\subsection{What Could Be the Weakness Points of Virtual Reality Classes to Teach English?}

When asked about the weakness of using VR to teach English Participants' responses were complementing the review literature as well in two main areas, first is that VR is believed to have two drawbacks that are the financial setbacks (Garrido-Iñigo \& Rodríguez-Moreno, 2015), and the inexperienced instructors who need training for implanting VR to teach English (Bonner \& Reinders, 2018; Merchant et al., 2014).

- Quotes indicating the high cost of implementing VR as a weakness:

'cost, especially for individuals looking for self-learning.'

'Financial setback: every student has to be offered the opportunity to use the VRC device.'

'the cost of VR comparing to the expected outcomes.'

- Quotes demonstrating instructors' unfamiliarity with VR as weakness point for implementing VR:

'Unexperienced instructor could be the weakness points.'

'VRCs require training courses for students.'

\subsection{What Could Be the Opportunities in-the Advantages of Using Virtual Reality to Teach English?}

The quoted advantages of using VR to teach English were Participants' responses were harmonizing the reviewed literature in that VR is proposed to meet new learners' expectations (Kessler, 2018; Lin \& Lan, 2015). and another advantage of VR is that it promotes customized and motivating learning (Chen, 2016; Freina \& Ott, 2015; Golonka et al., 2014; Kessler, 2018).

- Quotes showing that VR meets new learners' expectations as an advantage:

'might meet the learners' needs in term of more practical learning or more real learning experiences.'

'it might meet the desires of the current generation where tech is an important element of all different aspects of their lives.'

- Quotes demonstrating that VR promotes customized and motivating:

'To offer EFL learners and teachers a multimodal environment that can increase language learning outcomes.'

'... it offers language learners and teachers customized learning and teaching opportunities.

'It is a good replacement of traditional textbooks of learning/teaching English'

4.4 What Could Be the Threats-Disadvantages of Using Virtual Reality in Teaching English in the Saudi Context?

Findings revealed that there was one main drawback of using VR in teaching English in Saudi context, namely that VR could be a distraction for some students (Chen, 2016; Golonka et al., 2014; Kessler, 2018).

- Quotes indicating that VR might cause distraction:

'VRCs could be a distraction for poor students rather than an incentive.'

'Due exciting eye-catching nature of VRC, learners may focus on technology rather than language use.'

\section{Conclusion and Recommendations}

Both the academic sources reviewed and analyzed interviews for this study have indicated that the use of technology in teaching languages with the focus on the English language is one of the most studied yet argued topics. If the application of standard technologies like audio recorders, whiteboards, and projectors is viewed as an approach contributing to students' learning, the use of computer-based communication, online platforms, simulations, and virtual reality provokes a lot of questions. On the one hand, the application of virtual reality technologies is important for stimulating students' learning in an immersive context with the help of authentic sources and real-life situations. Such experience is unique and advantageous when students have no opportunities to communicate with native speakers or learn the language in the country they have chosen. It is 
stated in the literature that, and as the findings are complementing that using technologies and virtual reality, young people can strengthen their skills while avoiding the focus on traditional boring teaching tools.

As reviewed earlier and as the findings indicate, technology-enhanced language learning is viewed by researchers and practitioners as an essential step toward modernizing the approach to teaching students in this context, the focus is on stimulating learners' active communication and studying vocabulary and grammar within a positive, motivating and learner-centered computer-mediated environment.

On the other hand, the game-based nature of virtual reality for learning English can be viewed only as an additional component of teaching the language to motivate students. The reason is that not all teachers have developed skills in applying technologies in their classrooms, and this aspect influences the overall quality of education. Furthermore, students can use offered devices and software inappropriately and be distracted from focusing on the studied content.

In light of the findings of the study the researcher recommends that virtual reality be used in TEFL contexts of Saudi universities. The use of virtual reality can be practiced in traditional and online classes as to motivate students to practice their language skills in the most efficient manner. Such a context, surely, would get the students compensate the dearth of contact with native speakers and learn the language easily. The researcher also recommends that university instructors be trained in using innovative teaching tools as it raises their awareness of the effectiveness of modern technology. Such a step would increase the instructors' potentials in leading the role of integrating the latest e-learning tools like VR in EFL context. The researcher suggests further studies to be conducted in other Saudi universities with similar context of the targeted novice university or similar contexts in neighboring countries as more studies will contribute to international research on e-learning tools like VR for TEFL in higher education.

\section{References}

Bonner, E., \& Reinders, H. (2018). Augmented and Virtual Reality in The Language Classroom: Practical Ideas. Teaching English with Technology, 18(3), 33-53.

Chen, J. C. (2016). The crossroads of English language learners, task-based instruction, and 3D multi-user virtual learning in Second Life. Computers \& Education, 102, 152-171. https://doi.org/10.1016/j.compedu.2016.08.004

Chun, D., Kern, R., \& Smith, B. (2016). Technology in language use, language teaching, and language learning. The Modern Language Journal, 100(S1), 64-80. https://doi.org/10.1111/modl.12302

Fine, L. G. (2009). The SWOT Analysis: Using your strength to overcome Weaknesses. Using Opportunities to Overcome Threats.

Flick, U. (2018). An introduction to qualitative research. Sage Publications Limited.

Fowler, C. (2015). Virtual reality and learning: Where is the pedagogy? British Journal of Educational Technology, 46(2), 412-422. https://doi.org/10.1111/bjet.12135

Freina, L., \& Ott, M. (2015). A Literature Review on Immersive Virtual Reality in Education: State Of The Art and Perspectives. eLearning \& Software for Education, 1 .

Garrido-Iñigo, P., \& Rodríguez-Moreno, F. (2015). The reality of virtual worlds: Pros and cons of their application to foreign language teaching. Interactive Learning Environments, 23(4), 453-470. https://doi.org/10.1080/10494820.2013.788034

Godwin-Jones, R. (2016). Emerging Technologies Augmented Reality and Language Learning: From Annotated Vocabulary TO Place-Based Mobile Games. Language Learning \& Technology, 20(3), 9-19.

Golonka, E. M., Bowles, A. R., Frank, V. M., Richardson, D. L., \& Freynik, S. (2014). Technologies for foreign language learning: a review of technology types and their effectiveness. Computer Assisted Language Learning, 27(1), 70-105. https://doi.org/10.1080/09588221.2012.700315

Gray, D. E. (2013). Doing research in the real world. Sage.

Guthrie, G. (2010). Basic research methods: An entry to social science research. SAGE Publications India. https://doi.org/10.4135/9788132105961

Kessler, G. (2018). Technology and the future of language teaching. Foreign Language Annals, 51(1), 205-218. https://doi.org/10.1111/flan.12318

Li, K.-C., Tsai, C.-W., Chen, C.-T., Cheng, S.-Y., \& Heh, J.-S. (2015). The design of immersive English learning 
environment using augmented reality. Paper presented at the Ubi-Media Computing (UMEDIA), 2015 8th International Conference on. https://doi.org/10.1109/UMEDIA.2015.7297450

Lin, T.-J., \& Lan, Y.-J. (2015). Language Learning in Virtual Reality Environments: Past, Present, and Future. Journal of Educational Technology \& Society, 18(4).

Merchant, Z., Goetz, E. T., Cifuentes, L., Keeney-Kennicutt, W., \& Davis, T. J. (2014). Effectiveness of virtual reality-based instruction on students' learning outcomes in K-12 and higher education: A meta-analysis. Computers \& Education, 70, 29-40. https://doi.org/10.1016/j.compedu.2013.07.033

Morrison, R. (2017). Virtual Reality in the Language Learning Classroom. The Morning Watch: Educational and Social Analysis, 44(1-2 Fall).

Rahimi, A., Golshan, N. S., \& Mohebi, H. (2014). Virtual reality as a learning environment in Iranian EFL context: Personal, technical, and pedagogical. Procedia-Social and Behavioral Sciences, 136, 234-239. https://doi.org/10.1016/j.sbspro.2014.05.320

Solak, E., \& Cakir, R. (2015). Exploring the Effect of Materials Designed with Augmented Reality on Language Learners' Vocabulary Learning. Journal of Educators Online, 12(2), 50-72. https://doi.org/10.9743/JEO.2015.2.5

\section{Copyrights}

Copyright for this article is retained by the author, with first publication rights granted to the journal.

This is an open-access article distributed under the terms and conditions of the Creative Commons Attribution license (http://creativecommons.org/licenses/by/4.0/). 